\title{
Differential expression of M3 muscarinic receptors in progressive colon neoplasia and metastasis
}

\author{
Kunrong Cheng ${ }^{1,2}$, Aaron C. Shang ${ }^{2}$, Cinthia B. Drachenberg ${ }^{3}$, Min Zhan ${ }^{1,4}$, Jean- \\ Pierre Raufman ${ }^{1,2,5}$ \\ ${ }^{1}$ Veterans Affairs Maryland Healthcare System, Baltimore VA Medical Center, Baltimore, MD, USA \\ ${ }^{2}$ Department of Medicine, Division of Gastroenterology and Hepatology, University of Maryland School of Medicine, Baltimore, \\ MD, USA \\ ${ }^{3}$ Department of Pathology, University of Maryland School of Medicine, Baltimore, MD, USA \\ ${ }^{4}$ Department of Epidemiology and Public Health, University of Maryland School of Medicine, Baltimore, MD, USA \\ ${ }^{5}$ Marlene and Stewart Greenebaum Comprehensive Cancer Center, University of Maryland School of Medicine, Baltimore, \\ MD, USA
}

Correspondence to: Jean-Pierre Raufman, email: jraufman@medicine.umaryland.edu

Keywords: colon neoplasia, metastases, muscarinic receptors, matrix metalloproteinase-1, receptor expression

Received: November 30, 2016

Accepted: February 07, 2017

Published: February 18, 2017

\section{ABSTRACT}

M3 muscarinic receptor (M3R) activation promotes colon cancer cell proliferation, migration, and invasion in vitro. Although over-expression of CHRM3, the gene encoding $M 3 R$, is reported in primary colon cancers, expression of M3R itself has not been studied in colon neoplasia. We compared M3R expression in normal colon to colon adenomas, and primary and metastatic colon cancers. Compared to adjacent normal colon, CHRM3 expression was increased up to 128-fold in 10 of 18 consecutive surgical cancer specimens $(56 \%)$ and associated with metastatic spread $(P<0.05)$. To analyze M3R protein expression we interrogated 29 consecutive paraffin-embedded colon adenocarcinomas and adjacent normal colon using a specific anti-M3R antibody and immunoperoxidase staining. This revealed weak M3R expression in normal colonocytes, primarily on basolateral surfaces. In contrast, in $\mathbf{2 5}$ of 29 cancer tissues $(86 \%)$ we observed both cytoplasmic and plasma membrane over-expression of $M 3 R$; compared to normal epithelium, mean M3R staining intensity was increased more than two-fold in colon cancer $(P<0.001)$. M3R staining was also increased in 22 colon adenomas compared to adjacent normal colon $(P<0.001)$. In contrast, M3R staining intensity was not increased in lymph node or liver metastases. These findings suggest $M 3 R$ expression plays an important role in early progression and invasion of colon neoplasia but is less important once tumors have spread.

\section{INTRODUCTION}

Of five known muscarinic receptor subtypes, three that stimulate cellular signaling by means of phospholipid turnover (M1R, M3R, and M5R) are conditional oncogenes when expressed in cells capable of proliferation [1]. Of these three receptor subtypes, M3R are expressed widely in the gut and CHRM3, the gene encoding M3R, is reported to be uniquely over-expressed in colon cancer [2,3].

Muscarinic receptors are activated when bound by acetylcholine released from neurons or non-neuronal cells, including colon cancer cells [4]. M3R can also be activated by bile acids $[5,6]$; fecal bile acids have been implicated as tumor promoters by both epidemiological evidence in humans and bile acid-feeding studies in rodents $[7,8]$. In mice lacking a key intestinal bile acid transporter, we found increased spillage of bile acids into the colon was associated with augmented colon neoplasia and increased expression of M3R, a surrogate for M3R activation $[9,10]$.

In vitro studies using human colon cancer cells reveal that muscarinic receptor agonists stimulate cell proliferation, survival, migration, and invasion by complex mechanisms involving interacting post-M3R signaling pathways as well as cross-talk which activates epidermal growth factor receptors (EGFR) and a different set of post-receptor signaling cascades [11]. In particular, rapid, reversible activation of ERK $1 / 2$ regulates colon cancer cell proliferation and PI3K/AKT activation regulates cell survival and resistance to radiation $[11,12]$. In animal 
models relevant to sporadic and genetic human colon cancer, M3R activation stimulates colon cancer growth [13] and M3R deficiency attenuates tumor formation $[14,15]$. Collectively, these findings support an important role for M3R expression and activation in the progression of colon neoplasia.

Despite these intriguing observations, the expression of M3R protein in the normal human large intestine has not been compared to that in colon adenocarcinomas or other stages of colon neoplasia. To address this gap in knowledge we compared M3R expression in normal colon epithelium to that in colon adenomas, and primary and metastatic colon cancers. To avoid inter-individual variation, whenever possible we used matched specimens of normal colon along with primary and metastatic lesions from the same patient. Also, since in vitro studies show that M3R activation strongly induces expression of matrix metalloproteinase-1 (MMP1), an enzyme that degrades extracellular matrix [16] and whose expression correlates with advanced colon cancer stage, metastasis and poor prognosis $[17,18]$, we explored the association of $C H R M 3 / \mathrm{M} 3 \mathrm{R}$ and MMP1 expression in primary colon cancers.

As reported herein, we observed that measuring CHRM3 mRNA expression alone underestimates the extent to which M3R is over-expressed in colon neoplasia. Moreover, whereas M3R expression appears to be important for the progression of primary adenomas and adenocarcinomas and the development of metastatic disease, it appears less important in established lymph node and liver metastases. Finally, although MMP1 expression was robustly increased in almost all primary colon cancers, we were unable to demonstrate a quantitative relationship between the levels of CHRM3/ M3R and MMP1 expression. To our knowledge, this represents the first report of differential expression of M3R in different stages of colon neoplasia.

\section{RESULTS}

\section{Relative CHRM3 mRNA expression in colon adenocarcinomas compared to matched adjacent normal colon}

We initially sought to verify that $C H R M 3$, the gene encoding M3R, was over-expressed in colon cancer and to explore whether this was associated with any important clinical characteristics. As shown in Table 1, compared to adjacent normal colon, CHRM3 was over-expressed in 10 of 18 colon cancers $(56 \%)$, a value consistent with those reported by others $[2,3]$. In eight samples CHRM3 expression was increased 2- to 128-fold compared to that in matched adjacent normal colon; the great variation in CHRM3 expression most likely accounts for the failure to achieve statistical significance for the difference in
CHRM3 expression in colon cancer versus adjacent normal colon $(P=0.08)$.

Several studies suggest important biological difference between cancers of the left and right colon [19-21]; we examined the relationship between CHRM3 expression and the anatomic location, stage, and differentiation of colon cancer (Table 1). We observed no statistically significant relationship between CHRM3 expression and anatomic location or tumor differentiation $(P=0.35$ and 0.10 , respectively). There was, however, a significant relationship between the level of CHRM3 expression and the presence of colon cancer metastases; whereas metastases were absent in all 8 cancers lacking over-expression of CHRM3, metastatic disease was present in 5 of 10 individuals (50\%) in whom CHRM3 was over-expressed in the primary tumor $(P=0.04)$. This finding is consistent with our in vitro studies showing that treating human colon cancer cells with M3R agonists stimulates both cell migration and invasion, key features of tumor cells with metastatic capability [22-25].

\section{Relative M3R immunostaining in adenocarcinomas compared to adjacent normal colon}

To analyze M3R protein expression, we interrogated 29 consecutive paraffin-embedded colon adenocarcinomas and adjacent normal colon epithelium using a specific anti-M3R antibody and immunoperoxidase staining. The specificity of the anti-M3R antibody was verified using colon tissue obtained from M3R-deficient mice with targeted deletion of Chrm3 [15]. As shown in Supplementary Figure 1, a robust signal was observed in colon tissue from wild-type mice whereas no signal was observed in tissue from M3R-deficient animals or in control experiments performed without addition of the primary antibody.

It is noteworthy that the cellular distribution of M3R immunostaining was different in normal colon epithelium compared to that in malignant cells. Immunohistochemical analysis revealed weak M3R expression in normal colonocytes, primarily on basolateral surfaces (see examples in Figure 1A). In contrast, in colon cancer we observed both cytoplasmic and plasma membrane M3R staining (Figure 1A).

Compared to normal colon epithelium, mean M3R staining intensity was increased more than two-fold in colon cancer $(1.03 \pm 0.16$ vs. $2.45 \pm 0.14$ arbitrary units, mean $\pm \mathrm{SE} ; P<0.001)$; tumor M3R staining intensity exceeded that observed in paired adjacent normal epithelium in 25 of 29 samples (86\%) (Figure 1B). In concert with the data shown in Table 1, these findings provide strong support for the concept that CHRM3/ M3R expression is increased in colon cancer. As we observed for CHRM3 mRNA expression, there was 
Table 1: Levels of $C H R M 3$ mRNA expression in adenocarcinoma relative to matched adjacent normal colon

\begin{tabular}{|c|c|c|c|c|}
\hline $\begin{array}{c}\text { Specimen } \\
\text { Number }\end{array}$ & Anatomic Location & Tumor Stage & Tumor Differentiation & $\begin{array}{c}\text { CHRM3 mRNA } \\
\text { (fold-change) }\end{array}$ \\
\hline 1 & Left colon & T3N0M0 & Moderate & 0.32 \\
\hline 2 & Right colon & T4N0Mx & Well & 0.35 \\
\hline 3 & Left colon & T3N0Mx & Moderate & 0.57 \\
\hline 4 & Left colon & T2N0M0 & Moderate & 0.71 \\
\hline 5 & Left colon & T3N1Mx & Moderate & 0.72 \\
\hline 6 & Right colon & T4aN0Mx & Moderate & 0.73 \\
\hline 7 & Right colon & T3N2Mx & Well to Moderate & 0.78 \\
\hline 8 & Left colon & $\mathrm{T} 2 \mathrm{~N} 1 \mathrm{Mx}$ & Well & 1.00 \\
\hline 9 & Right colon & T3N0M0 & Poor & 1.35 \\
\hline 10 & Left colon & T4bM1 & Moderate & 1.74 \\
\hline 11 & Right colon & T4N0Mx & Poor & 2.80 \\
\hline 12 & Right colon & T3N1M1 & Moderate & 3.62 \\
\hline 13 & Right colon & T3N0Mx & Well & 4.10 \\
\hline 14 & Right colon & T3N2bM1 & Moderate & 5.21 \\
\hline 15 & Left colon & $\mathrm{T} 2 \mathrm{~N} 0 \mathrm{Mx}$ & Moderate to Poor & 6.98 \\
\hline 16 & Right colon & T4aN2M1 & Poor & 24.57 \\
\hline 17 & Left colon & T3N1Mx & Moderate & 31.05 \\
\hline 18 & Right colon & T3N0M1 & Well & 128.18 \\
\hline
\end{tabular}

Levels of CHRM3 mRNA expression were normalized to those of $\beta_{2}$-microglobulin. Results represent the means of triplicate determinations and are expressed as fold-change relative to values obtained in adjacent normal colon tissue.

no statistically significant relationship between M3R immunostaining and anatomic location or tumor differentiation.

\section{Relative M3R immunostaining in adenomas compared to adjacent normal colon}

Next, we sought to determine whether M3R overexpression is apparent at earlier stages of colon neoplasia. Based on the importance of M3R activation on colon cancer cell proliferation and survival, we hypothesized that increased M3R expression would occur early in the development of colon neoplasia. It is generally accepted that adenocarcinomas of the colon derive from pre-existing adenomas [24, 26]. Hence, we compared M3R expression in colon adenomas to that in matched samples of normal colon epithelium obtained from the same individual.

As shown in Figure 1C, we also observed increased $\mathrm{M} 3 \mathrm{R}$ expression in adenomas compared to normal colon. In a set of 22 adenomas compared to normal colon, M3R immunostaining was significantly increased compared to adjacent normal colon $(2.16 \pm 0.14$ vs. 1.02 \pm 0.11 arbitrary units, mean \pm SE; $P<0.001$; Figure 1D). Although it was not possible to compare M3R expression directly in the progression of an adenoma to an adenocarcinoma, the two-fold increased M3R over- expression in adenomas (Figure 1D) was similar to that observed in adenocarcinomas (Figure 1B), consistent with the hypothesis that over-expression of M3R is an early step in colon neoplasia.

\section{Relative M3R immunostaining in lymph node and liver metastases compared to matched primary colon adenocarcinomas and normal colon epithelium}

We next compared M3R immunostaining in lymph node (Figure 2A, 2B) and liver metastases (Figure 2C, 2D) to that in matched normal colon and primary colon cancers ( $n=7$ for lymph node and $n=12$ for liver metastases). As observed above (Figure 1B), the level of M3R immunostaining was increased approximately two-fold in primary tumors compared to normal colon epithelium, but M3R immunostaining was only minimally increased in lymph node and liver metastases $(1.00 \pm 0.36$ vs. $0.50 \pm 0.26$ for lymph node metastases vs. normal colon and $1.04 \pm 0.28$ vs. $0.92 \pm 0.19$ for liver metastases vs. normal colon, mean $\pm \mathrm{SE}$; neither comparison was statistically significant) (Figures 2B and 2D). When we compared mean M3R immunostaining in all available samples, we again observed that immunostaining was the same as control (normal colon epithelium) in lymph 
node metastases and only minimally elevated in liver metastases (Table 2); as before, the only comparisons that achieved strong statistical significance were M3R staining in adenomas and adenocarcinomas versus normal colon epithelium.

\section{Relationship of CHRM3/M3R and MMP1 mRNA over-expression in colon cancer}

In human colon cancer cells, M3R activation induces a 30- to 50-fold increase in the levels of MMP1 mRNA expression, an action that appears critical for colon cancer cell invasion $[16,23]$. To explore the relationship between CHRM3 and MMP1 mRNA expression we used the same 18-sample dataset shown in Table 1. Compared to normal colon, we observed robust MMP1 mRNA over-expression in 16 of the 18 cancer specimens $(89 \%$; Supplementary Table 2), but we were unable to identify a quantitative relationship between $C H R M 3$ and MMP1 expression levels. Although the mean fold-change in MMP1 mRNA level in cancers with increased CHRM3 expression (samples 9-18) was almost 10-fold greater than those in cancers with reduced CHRM3 expression (samples 1-7) (MMP1 mRNA fold-change, 1042.5 \pm 711.0

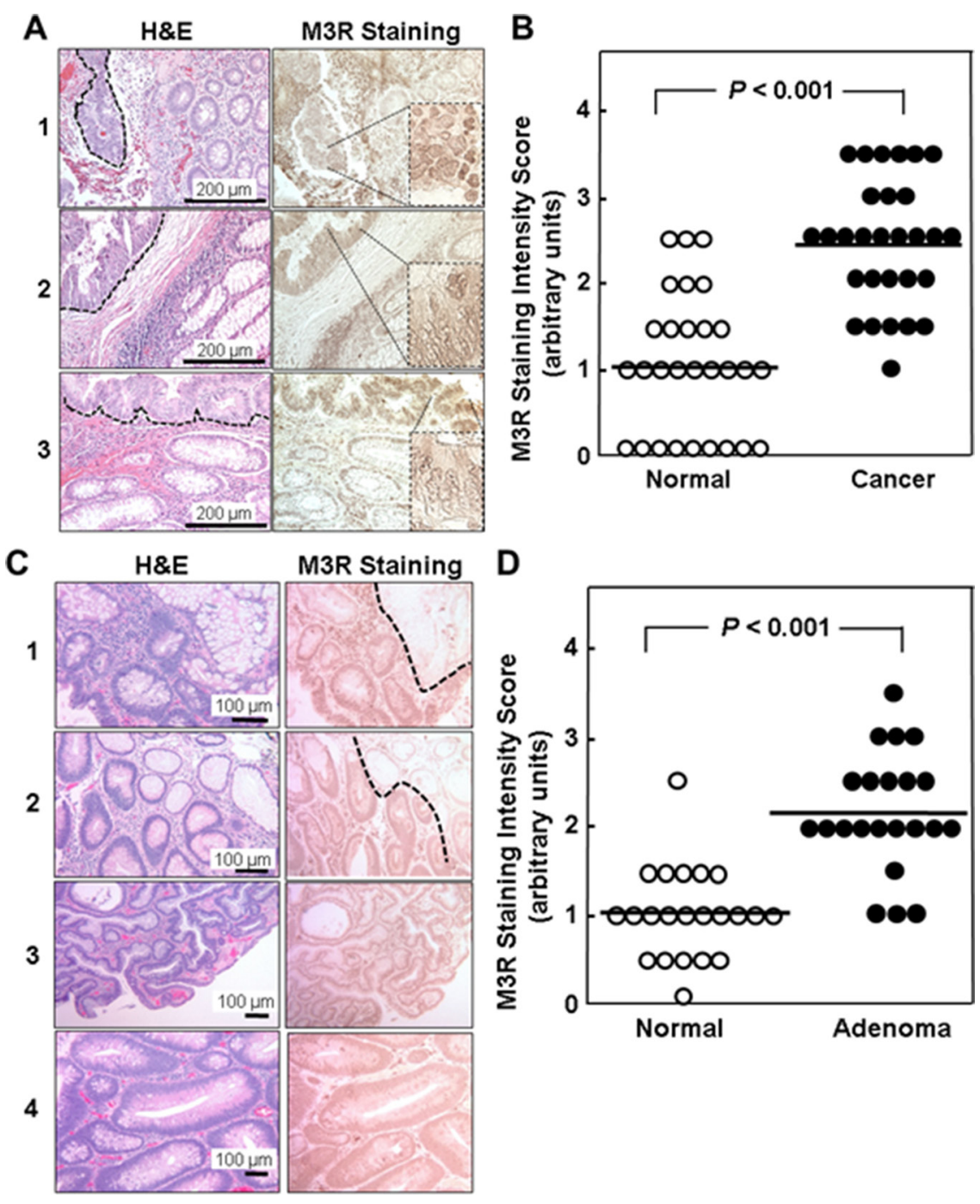

Figure 1: Relative M3R immunostaining in adenocarcinomas and adenomas compared to adjacent normal colon from the same patient. (A) H\&E and M3R immunoperoxidase staining is shown for three representative tissue samples. In normal colon, M3R is expressed weakly, primarily on basolateral surfaces of colonocytes. In well- and moderately-differentiated cancer (delineated by dashed lines in H\&E sections) focal and diffuse M3R over-expression is seen in the cytoplasm and plasma membranes. (B). M3R staining intensity in 29 colon adenocarcinomas and adjacent normal colon was scored in 0.5 increments on a scale from 1 to 3 arbitrary units, where 0 represents absent and 3 maximal staining. Symbols represent individual tissue samples and horizontal bars represent means. (C) H\&E and M3R immunoperoxidase staining is shown for four representative adenomas. In samples 1 and 2, normal colon epithelium present in the upper right hand corner of the images, delineated by dashed lines, shows less M3R staining compared to adenoma. (D) Staining intensity in 22 adenomas was scored on a scale from 1 to 3 arbitrary units in 0.5 increments where 0 is absent and 3 is maximal staining. Symbols represent individual tissue samples. Horizontal bars represent means. 
Table 2: Results of M3R immunohistochemical staining analysis

\begin{tabular}{|c|c|c|c|c|}
\hline Tissue Sample & $\begin{array}{l}\text { Mean M3R Staining } \\
\text { Score (au) }\end{array}$ & SE & $\begin{array}{c}\text { Adjusted } P \text { versus Normal Colon } \\
\text { Epithelium }\end{array}$ & $\begin{array}{l}\text { Number of } \\
\text { Samples }\end{array}$ \\
\hline Normal colon epithelium & 0.98 & 0.09 & reference & 64 \\
\hline Colon adenoma & 2.16 & 0.14 & $<0.001$ & 22 \\
\hline Colon adenocarcinoma & 2.51 & 0.11 & $<0.001$ & 42 \\
\hline Lymph node metastasis & 0.88 & 0.34 & 1.0 & 8 \\
\hline Liver metastasis & 1.32 & 0.28 & 0.19 & 17 \\
\hline
\end{tabular}

*Adjusted $P$ values were calculated based on a linear mixed model with Dunnett-Hsu's multiple comparison procedure.

vs $119.5 \pm 60.8$; mean $\pm \mathrm{SE}$ ), due to considerable intersample variation and large standard errors this difference failed to achieve statistical significance.

Next, we used a specific anti-MMP1 antibody and immunoperoxidase staining to measure MMP1 protein expression in formalin-fixed paraffin-embedded tissue. Unlike membrane-anchored M3R, MMP1 is a secreted protein that can be washed away during tissue processing. Thus, as shown in Supplementary Figure 2, the detection of MMP1 staining was limited to peri-cellular surfaces and mucin vacuoles. Applying immunofluorescence to determine the relationship between M3R and MMP1 expression in normal colon, adenoma, and adenocarcinoma from the same individual appeared to show the redistribution of MMP1 staining from glandular lumens in normal colon to cell surfaces in cancer (Supplementary Figure 3). Although we could identify areas of intense over-expression of both M3R and MMP1 in adenoma and adenocarcinoma tissue (Supplementary Figure 3), we were unable to quantify the relationship between such changes consistently.

\section{DISCUSSION}

This first report of differential expression of M3R in colon neoplasia provides useful information. First, it appears that increased M3R expression is an early feature of colon neoplasia - compared to adjacent normal colon, M3R expression is increased in adenomas to nearly the same extent as in adenocarcinomas. Second, increased expression of M3R in primary colon cancers appears to be associated with the presence of metastatic disease. This may reflect the in vitro observation that activation of M3R stimulates colon cancer cell invasion, a prelude to tumor dissemination $[22,23,25]$. Third, it appears that M3R expression is less important for the sustenance or progression of colon cancer metastases than for the growth and spread of primary colon neoplasia. We base this speculation on the observations that the levels of M3R expression in both lymph node and liver metastases are lower than in matched primary colon adenocarcinomas. Fourth, in addition to increased M3R expression in colon cancer we noted a change in the intracellular distribution of M3R immunostaining from being primarily associated with basolateral membranes to a broader distribution within cancer cells, including cytoplasmic localization. This finding is consistent with M3R transition from a quiescent plasma membrane-associated localization in normal colon epithelium to a more dynamic, functional role in cancer that likely involves M3R recycling. In addition to M3R expression serving as a surrogate marker for M3R activation [9] this suggests that the broader cellular distribution of immunostaining could provide an additional marker of M3R activation.

It appears that relying on CHRM3 expression underestimates the degree to which M3R itself is overexpressed; whereas we found increased CHRM3 mRNA expression in $56 \%$ of colon cancers compared to adjacent normal colon, we detected M3R protein over-expression in $86 \%$ of a larger set of tissue samples. This begs a question we cannot answer with certainty - Why does measuring CHRM3 mRNA expression underestimate M3R overexpression in colon cancer? This, perhaps not surprisingly, weak correlation between gene and protein expression has been considered by others [27]. It is important to remember that protein abundance reflects a dynamic balance between mRNA processing and degradation as well as protein translation, localization, modification, and hydrolysis. Thus, CHRM3 transcript abundance may not be the major determinant of M3R protein abundance. Factors like the actions of miRNA's, the relative fragility of mRNA compared to protein, and others may also play a role [27, 28]. For example, substantial RNA degradation may occur between the time colon tissue is resected and frozen.

The experimental design used herein has several strengths. Chief amongst these is that whenever possible we compared normal colon, adenomas, adenocarcinomas, and metastases in matched tissue samples from the same individuals. Nonetheless, we recognize that this work has limitations. One consequence of studying tissue from the same individuals is that for lymph node and liver metastases we had relatively small sample sizes to work with. Another limitation is that ours was a retrospective analysis; thus, although increased CHRM3 expression in the primary colon cancer appears to make it more likely metastases are present, we have not studied this prospectively. 
MMP1, a matrix metalloproteinase associated with more aggressive tumors and whose expression is induced by M3R activation in human colon cancer cells, was almost uniformly over-expressed in adenocarcinomas compared to normal colon. Whereas the levels of MMP1 over-expression were generally associated with those of M3R expression (MMP1 and M3R were over-expressed in $89 \%$ and $86 \%$, respectively, of colon cancers), both large

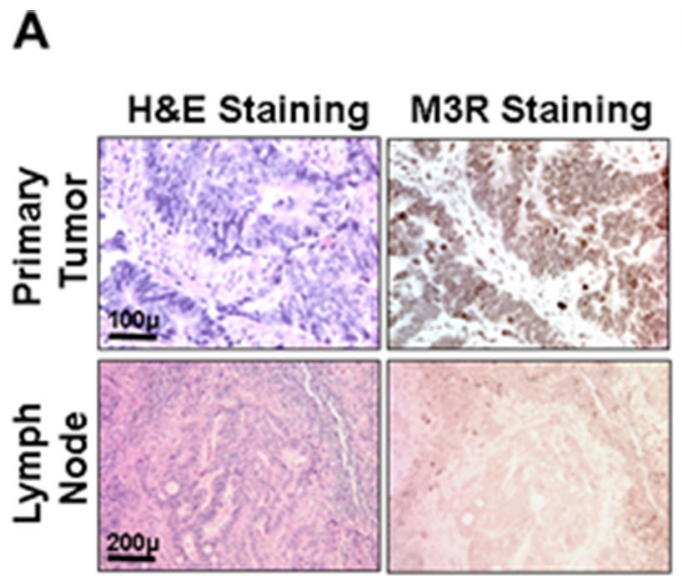

B
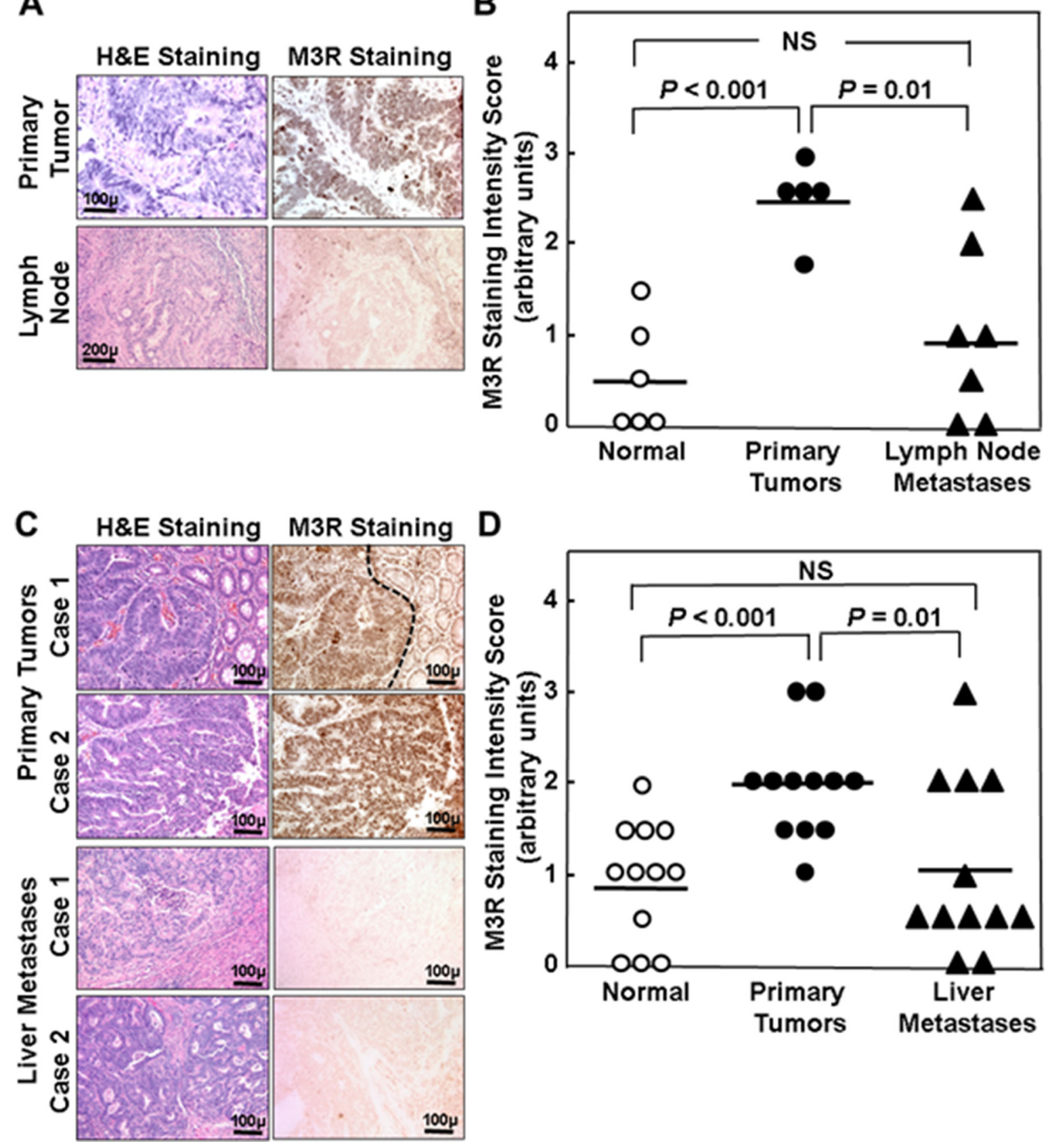

Figure 2: Relative M3R immunostaining in primary adenocarcinoma compared to lymph node and liver metastases from the same patient. (A) H\&E and M3R immunoperoxidase staining is shown for a representative set of primary adenocarcinoma and lymph node metastasis from the same patient. (B) Staining intensity for matched normal colon epithelium, primary adenocarcinoma, and lymph node metastases from seven different patients was scored on a scale from 1 to 3 arbitrary units in 0.5 increments where 0 is absent and 3 is maximal staining. Symbols represent individual tissue samples. Horizontal bars represent means. (C) H\&E and M3R immunoperoxidase staining is shown for two representative sets of adenocarcinoma (top panels) and liver metastases (bottom panels) from the same two patients. Normal colon epithelium with weak M3R immunostaining can be seen to the right of the primary tumor in Case 1 (delineated by dashed line). (D) Staining intensity for matched normal colon epithelium, primary adenocarcinoma, and liver metastases from 12 different patients was scored on a scale from 1 to 3 arbitrary units in 0.5 increments where 0 is absent and 3 is maximal staining. Symbols represent individual tissue samples. Horizontal bars represent means. 
inter-sample variations in $M M P 1$ expression and limited sample size contributed to our inability to identify a direct correlation between these events. It is also important to note that M3R activation, not $C H R M 3 / \mathrm{M} 3 \mathrm{R}$ expression, drives the induction of MMP1 expression [23, 29]. So, even though $C H R M 3 / \mathrm{M} 3 \mathrm{R}$ expression may be a surrogate for M3R activation and we detected a general association between CHRM3 and MMP1 expression, it is perhaps not surprising that this was insufficient to form the basis for a quantitative relationship between $C H R M 3 / \mathrm{M} 3 \mathrm{R}$ and MMP1 expression.

In conclusion, we report the novel findings that M3 muscarinic receptors are expressed differentially in various stages of colon neoplasia, and that increased M3R expression in primary adenocarcinomas of the colon may be a biomarker for metastatic potential. We also identified changes in the cellular distribution of M3R in colon adenomas and carcinomas that are most likely indicative of activated M3R signaling, and receptor internalization and recycling. Overall, these observations are consistent with an emerging body of literature that highlights the importance of muscarinic receptor expression and activation of M3R signaling cascades in cancer progression [30].

\section{MATERIALS AND METHODS}

\section{Human tissues}

To examine M3R (CHRM3) and MMP1 gene and protein expression, we used archived pre-existing deidentified surgical specimens of colon cancer and adjacent normal colon epithelium (approved by the University of Maryland School of Medicine Institutional Review Board and the Baltimore VA Research and Development Committee). To ensure sufficient material for expression analysis and uniform distribution of immunohistochemical staining throughout a sample, we used only surgical tissue specimens (i.e. smaller, endoscopic biopsies were not used).

\section{Immunohistochemistry}

Formalin-fixed paraffin-embedded tumor sections were immunostained using specific antibodies against both human and mouse M3R from Alomone Labs (Jerusalem, Israel) and against MMP1 from Santa Cruz (Dallas, $\mathrm{TX}$ ), and following the vendors' recommendations. Stained tumor sections were examined with a Nikon $80 i$ photomicroscope at $200 \mathrm{x}$ magnification. Sections were reviewed and scored by a senior pathologist (CD) masked to tissue origin. To minimize variation, all tumor sections were examined and photographed using the same microscope settings.

\section{Quantitative RT-PCR (qPCR)}

First-strand cDNAs were synthesized from $5 \mu \mathrm{g}$ RNA (Superscript III First Strand Synthesis System for RT-PCR, Invitrogen). qPCR was performed using 50 ng cDNA, the SYBR Green PCR Master Mix (Applied Biosystems), and forward and reverse primers (final concentration $0.5 \mu \mathrm{M}$ in sample volumes of $20 \mu \mathrm{l}$ ). Primers (Supplementary Table 1) were designed to span introns using the National Center for Biotechnology Information nucleotide database SIM-4 gene alignment program and on-line software (www.genscript.com/ssl-bin/app/primer). qPCR was performed using the 7900HT Fast System (ABI) with Power SYBR Green Master Mix (ABI). PCR conditions included $5 \mathrm{~min}$ at $95^{\circ} \mathrm{C}$ followed by 37 cycles of $95^{\circ} \mathrm{C}$ for 15 seconds, $60^{\circ} \mathrm{C}$ for 20 seconds, and $72^{\circ} \mathrm{C}$ for 40 seconds and a final cycle at $95^{\circ} \mathrm{C}$ for 15 seconds, $60^{\circ} \mathrm{C}$ for 15 seconds, and $95^{\circ} \mathrm{C}$ for 15 seconds. PCR data were analyzed using ABI instrument software SDS 2.1. Expression of $C H R M 3$ and $M M P 1$ was normalized to $\beta 2$ microglobulin $(B 2 M)$, a preferable housekeeping gene for analysis of colon cancer.[31] Quantitative qPCR data were evaluated using the comparative $C_{\mathrm{T}}\left(2^{-\Delta \Delta C \mathrm{~T}}\right)$ method.[32]

\section{Statistical analysis}

To compare fold-changes in CHRM3 expression we used the Wilcoxon signed rank test on logtransformed data. Fisher's exact test was used to analyze contingency tables for small sample sizes. To calculate adjusted $P$ values for comparisons of M3R immunostaining we employed linear mixed model analysis on the ranks of staining scores and the DunnettHsu method for multiple comparisons. Statistical significance was set at $P<0.05$.

\section{CONFLICTS OF INTEREST}

The authors declare no conflicts of interest.

\section{FUNDING}

This work was supported in part by Merit Review Award \# BX002129 from the United States (U.S.) Department of Veterans Affairs Biomedical Laboratory Research and Development Program (to J-P.R.). The contents do not represent the views of the U.S. Department of Veterans Affairs or the United States Government. This work was also supported by NIH grant R21 DK093406 (to J-P.R.).

\section{Authors' contributions}

Kunrong Cheng - Study Design, Experimental Methods, Manuscript Preparation; Aaron C. Shang Experimental Methods, Manuscript Review; Cinthia B. Drachenberg - Study Design, Experimental Methods, Manuscript Review; Min Zhan - Statistical Analysis, Manuscript Review; Jean-Pierre Raufman - Study Design, Experimental Methods, Manuscript Preparation and Final Review. 


\section{REFERENCES}

1. Gutkind JS, Novotny EA, Brann MR, Robbins KC. Muscarinic acetylcholine receptor subtypes as agonistdependent oncogenes. Proc Natl Acad Sci USA. 1991; 88:4703-4707.

2. Frucht H, Jensen RT, Dexter D, Yang WL, Xiao Y. Human colon cancer cell proliferation mediated by the M3 muscarinic cholinergic receptor. Clin Cancer Res. 1999; $5: 2532-2539$

3. Yang WL, Frucht H. Cholinergic receptor up-regulates COX-2 expression and prostaglandin E production in colon cancer cells. Carcinogenesis. 2000; 21:1789-1793.

4. Cheng K, Samimi R, Xie G, Shant J, Drachenberg C, Wade M, Davis RJ, Nomikos G, Raufman JP. Acetylcholine release by human colon cancer cells mediates autocrine stimulation of cell proliferation. Am J Physiol Gastrointest Liver Physiol. 2008; 295:G591-597.

5. Cheng K, Raufman JP. Bile acid-induced proliferation of a human colon cancer cell line is mediated by transactivation of epidermal growth factor receptors. Biochem Pharmacol. 2005; 70:1035-1047.

6. Cheng K, Chen Y, Zimniak P, Raufman JP, Xiao Y, Frucht H. Functional interaction of lithocholic acid conjugates with M3 muscarinic receptors on a human colon cancer cell line. Biochim Biophys Acta. 2002; 1588:48-55.

7. Bernstein C, Holubec H, Bhattacharyya AK, Nguyen H, Payne CM, Zaitlin B, Bernstein H. Carcinogenicity of deoxycholate, a secondary bile acid. Arch Toxicol. 2011; $85: 863-871$.

8. Flynn C, Montrose DC, Swank DL, Nakanishi M, Ilsley JN, Rosenberg DW. Deoxycholic acid promotes the growth of colonic aberrant crypt foci. Mol Carcinog. 2007; 46:60-70.

9. Song P, Sekhon HS, Fu XW, Maier M, Jia Y, Duan J, Proskosil BJ, Gravett C, Lindstrom J, Mark GP, Saha S, Spindel ER. Activated cholinergic signaling provides a target in squamous cell lung carcinoma. Cancer Res. 2008; 68:4693-4700.

10. Raufman JP, Dawson PA, Rao A, Drachenberg CB, Heath J, Shang AC, Hu S, Zhan M, Polli JE, Cheng K. Slc10a2-null mice uncover colon cancer-promoting actions of endogenous fecal bile acids. Carcinogenesis. 2015; 36:1193-1200.

11. Cheng K, Zimniak P, Raufman JP. Transactivation of the epidermal growth factor receptor mediates cholinergic agonist-induced proliferation of H508 human colon cancer cells. Cancer Res. 2003; 63:6744-6750.

12. Shant J, Cheng K, Marasa BS, Wang JY, Raufman JP. Aktdependent NF-kappaB activation is required for bile acids to rescue colon cancer cells from stress-induced apoptosis. Exp Cell Res. 2009; 315:432-450.

13. Peng Z, Heath J, Drachenberg C, Raufman JP, Xie G. Cholinergic muscarinic receptor activation augments murine intestinal epithelial cell proliferation and tumorigenesis. BMC Cancer. 2013; 13:204.
14. Raufman JP, Shant J, Xie G, Cheng K, Gao XM, Shiu B, Shah N, Drachenberg CB, Heath J, Wess J, Khurana S. Muscarinic receptor subtype-3 gene ablation and scopolamine butylbromide treatment attenuate small intestinal neoplasia in Apcmin/+ mice. Carcinogenesis. 2011; 32:1396-1402.

15. Raufman JP, Samimi R, Shah N, Khurana S, Shant J, Drachenberg C, Xie G, Wess J, Cheng K. Genetic ablation of M3 muscarinic receptors attenuates murine colon epithelial cell proliferation and neoplasia. Cancer Res. 2008; 68:3573-3578.

16. Kessenbrock K, Plaks V, Werb Z. Matrix metalloproteinases: regulators of the tumor microenvironment. Cell. 2010; 141:52-67.

17. Sunami E, Tsuno N, Osada T, Saito S, Kitayama J, Tomozawa S, Tsuruo T, Shibata Y, Muto T, Nagawa H. MMP-1 is a prognostic marker for hematogenous metastasis of colorectal cancer. Oncologist. 2000; 5:108-114.

18. Murray GI, Duncan ME, O’Neil P, Melvin WT, Fothergill JE. Matrix metalloproteinase-1 is associated with poor prognosis in colorectal cancer. Nat Med. 1996; 2:461-462.

19. Sugai T, Habano W, Jiao YF, Tsukahara M, Takeda Y, Otsuka K, Nakamura S. Analysis of molecular alterations in left- and right-sided colorectal carcinomas reveals distinct pathways of carcinogenesis: proposal for new molecular profile of colorectal carcinomas. J Mol Diagn. 2006; 8:193-201.

20. Watanabe T, Kobunai T, Toda E, Yamamoto Y, Kanazawa T, Kazama Y, Tanaka J, Tanaka T, Konishi T, Okayama Y, Sugimoto Y, Oka T, Sasaki S, et al. Distal colorectal cancers with microsatellite instability (MSI) display distinct gene expression profiles that are different from proximal MSI cancers. Cancer Res. 2006; 66:9804-9808.

21. Azzoni C, Bottarelli L, Campanini N, Di Cola G, Bader G, Mazzeo A, Salvemini C, Morari S, Di Mauro D, Donadei E, Roncoroni L, Bordi C, Sarli L. Distinct molecular patterns based on proximal and distal sporadic colorectal cancer: arguments for different mechanisms in the tumorigenesis. Int J Colorectal Dis. 2007; 22:115-126.

22. Belo A, Cheng K, Chahdi A, Shant J, Xie G, Khurana S, Raufman JP. Muscarinic receptor agonists stimulate human colon cancer cell migration and invasion. Am J Physiol Gastrointest Liver Physiol. 2011; 300:G749-760.

23. Raufman JP, Cheng K, Saxena N, Chahdi A, Belo A, Khurana S, Xie G. Muscarinic receptor agonists stimulate matrix metalloproteinase 1-dependent invasion of human colon cancer cells. Biochem Biophys Res Commun. 2011; 415:319-324.

24. Markowitz SD, Bertagnolli MM. Molecular origins of cancer: Molecular basis of colorectal cancer. N Engl J Med. 2009; 361:2449-2460.

25. Hanahan D, Weinberg RA. Hallmarks of cancer: the next generation. Cell. 2011; 144:646-674.

26. Vogelstein B, Kinzler KW. The Path to Cancer-Three Strikes and You're Out. N Engl J Med. 2015; 373:1895-1898. 
27. Vogel C, Marcotte EM. Insights into the regulation of protein abundance from proteomic and transcriptomic analyses. Nat Rev Genet. 2012; 13:227-232.

28. Hu S, Liu L, Chang EB, Wang JY, Raufman JP. Butyrate inhibits pro-proliferative miR-92a by diminishing c-Mycinduced miR-17-92a cluster transcription in human colon cancer cells. Mol Cancer. 2015; 14:180.

29. Xie G, Cheng K, Shant J, Raufman JP. Acetylcholineinduced activation of M3 muscarinic receptors stimulates robust matrix metalloproteinase gene expression in human colon cancer cells. Am J Physiol Gastrointest Liver Physiol. 2009; 296:G755-763.
30. Shah N, Khurana S, Cheng K, Raufman JP. Muscarinic receptors and ligands in cancer. Am J Physiol Cell Physiol. 2009; 296:C221-232.

31. Dydensborg AB, Herring E, Auclair J, Tremblay E, Beaulieu JF. Normalizing genes for quantitative RT-PCR in differentiating human intestinal epithelial cells and adenocarcinomas of the colon. Am J Physiol Gastrointest Liver Physiol. 2006; 290:G1067-1074.

32. Schmittgen TD, Livak KJ. Analyzing real-time PCR data by the comparative C(T) method. Nat Protoc. 2008; 3:1101-1108. 